\title{
Over-the-scope clip for a pharyngeal perforation caused by a self-inflicted stab wound to the neck
}

An 86-year-old woman was admitted to the emergency room with a self-inflicted 3 -cm horizontal wound to the left lateral side of her neck between the cricoid inferiorly and the angle of the mandible superiorly. Pain, tenderness, and bloody saliva suggested a penetrating zone II neck perforation [1]. No signs of significant injury, such as severe active hemorrhage, bruit, pulse deficit, hoarseness, stridor, respiratory distress, hemiparesis, expanding hematoma, or subcutaneous emphysema, were observed clinically or found on computed tomography (CT) scanning.

The patient, having been given a general anesthetic with orotracheal intubation, underwent surgical exploration [2]. The sternocleidomastoid muscle was almost sectioned, the left submandibular gland was lacerated up to the trachea, but there were no vascular or nerve injuries. Intraoperative flexible endoscopy identified a 9-mm clean-cut perforation of the hypopharynx when the tip of a rubber probe was pushed through the wound (॰ Fig. 1a).

An 11-mm traumatic over-the-scope clip (OTSC; Ovesco Endoscopy, Tübingen, Germany) with an anchor that grasped and invaginated the margins into the cap was used to close the perforation ( $\nabla$ Fig. 1 b). No technical difficulties were encountered and there were no adverse events. The neck wound was sutured leaving an external drain in place.

After 24 hours, a Gastrografin swallow and a further CT scan were performed, which showed no evidence of leakage ( Fig.2). The patient resumed an oral diet, and reported mild odynophagia not requiring specific therapy that decreased progressively and disappeared after 5 weeks, at which time it appeared that the OTSC had been swallowed, as it was no longer visible on weekly radiographs of the neck.

This unique case suggests that an OTSC can be easily and successfully deployed in the hypopharynx, as in other gastrointestinal locations [3], despite the narrow operating space, and is associated with mild odynophagia. The OTSC expands the
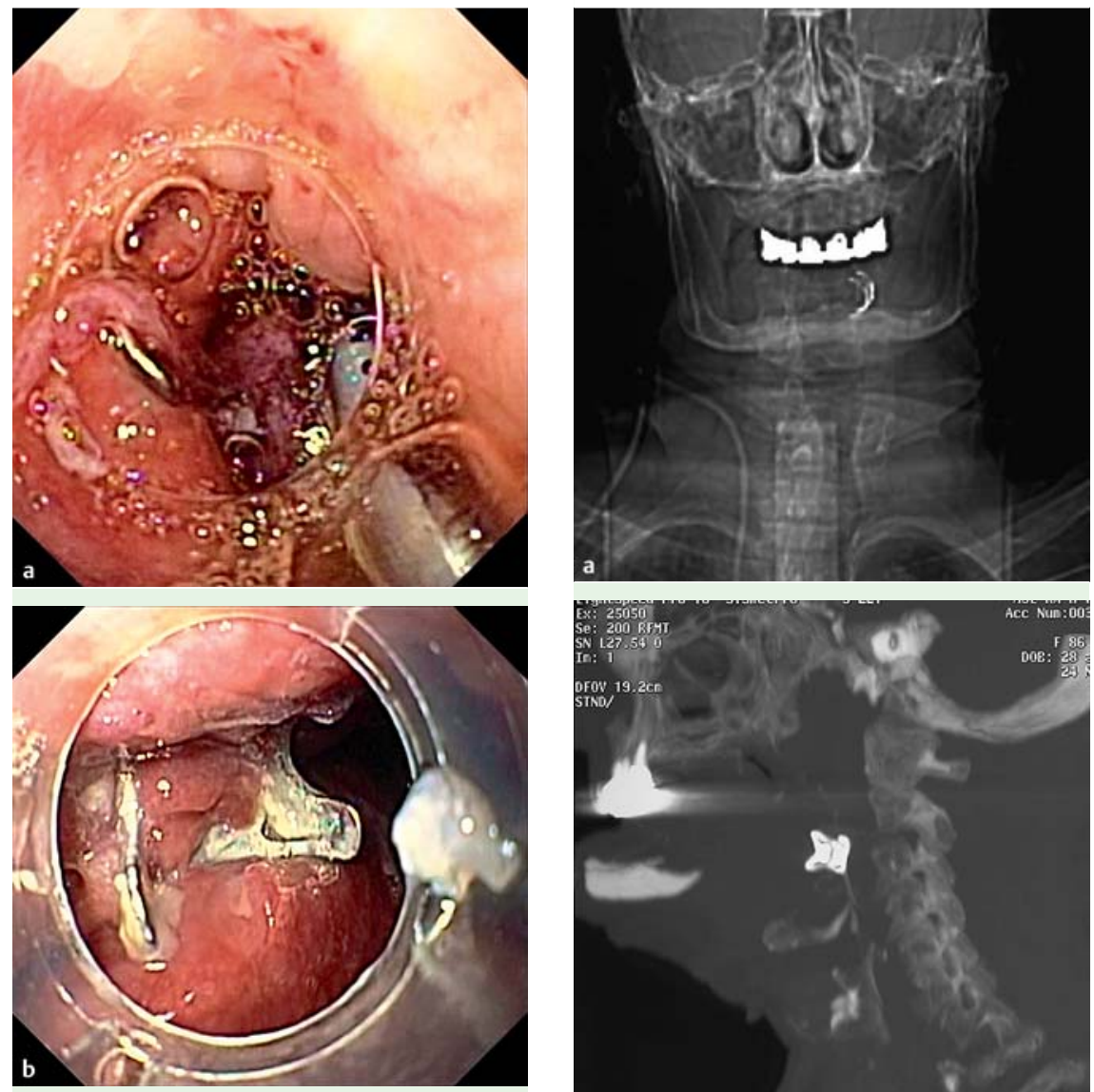

Fig. 1 Endoscopic images in an 86-year-old woman with a self-inflicted $3-\mathrm{cm}$ wound to the left lateral side of the neck showing: a the tip of a probe appearing through the wound and the hypopharyngeal perforation; b an over-the-scope clip (OTSC) after it had been released to close the perforation in the hypopharynx.

possible treatment options for minimally invasive flexible endoscopic closure of accidental and iatrogenic pharyngeal perforations that are potentially devastating [4] and difficult to treat with standard through-the-scope clips, and which may otherwise require prolonged conservative treatment or surgical intervention [5].

Endoscopy_UCTN_Code_TTT_1AO_2AN

Competing interests: None
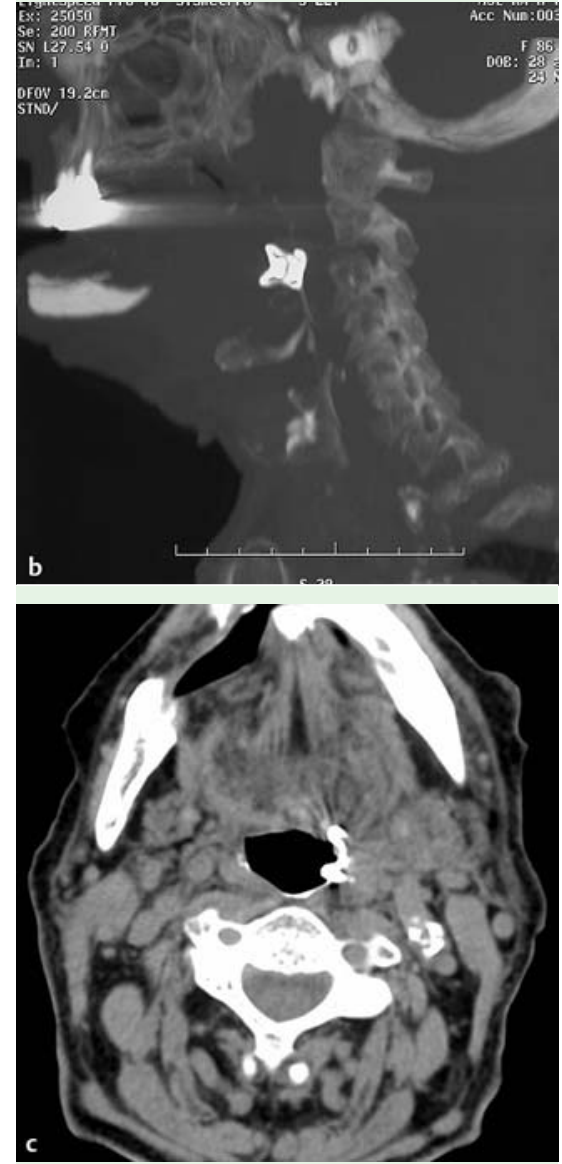

Fig. 2 A computed tomography (CT) scan performed 24 hours after placement of the over-the-scope clip (OTSC) in the hypopharynx: a the frontal scout image; $\mathbf{b}$ the sagittal scout image; $c$ a transverse image. 


\section{Federico lacopini', Marc Oliver Schurr ${ }^{2}$, Guido Costamagna ${ }^{3}$, Agostino Scozzarro ${ }^{1}$}

${ }^{1}$ Department of Gastroenterology and Endoscopy, Ospedale S. Giuseppe, Rome, Italy

2 Department of Surgical Digestive Endoscopy, Policlinico Gemelli, Rome, Italy

${ }^{3}$ Steinbeis University Berlin, IHCl-Institute, Tübingen, Germany

\section{References}

1 Tisherman SA, Bokhari F, Collier B et al. Clinical practice guideline: penetrating zone II neck trauma. J Trauma 2008; 64: 1392 1405

2 Biffl WL, Moore EE, Rehse DH et al. Selective management of penetrating neck trauma based on cervical level of injury. Am J Surg 1997; 174: 678-682

3 Voermans RP, Le Moine O, von Renteln D et al. Efficacy of endoscopic closure of acute perforations of the gastrointestinal tract. Clin Gastroenterol Hepatol 2012; 10: 603-608

4 Eloubeidi MA, Tamhane A, Lopes TL et al. Cervical esophageal perforations at the time of endoscopic ultrasound: a prospective evaluation of frequency, outcomes, and patient management. Am J Gastroenterol 2009; 104: 53-56

5 Baron TH, Wong Kee Song LM, Zielinski MD et al. A comprehensive approach to the management of acute endoscopic perforations (with videos). Gastrointest Endosc 2012; 76: $838-859$
Bibliography

DOI http://dx.doi.org/

10.1055/s-0033-1359126

Endoscopy 2014; 46: E42-E43

(C) Georg Thieme Verlag KG

Stuttgart · New York

ISSN 0013-726X

\section{Corresponding author}

Federico lacopini, MD

UOC Gastroenterology and Digestive Endoscopy Ospedale S. Giuseppe

Via del mare 1, Albano L.

Rome 00041

Italy

Fax: +39-06-93273216

federico.iacopini@gmail.com 